\title{
Calculations of near-field emissions in frequency-domain into time- dependent data with arbitrary wave form transient perturbations
}

\author{
Yang Liu ${ }^{1}$, Blaise Ravelo ${ }^{1}$ and Jalel Ben Hadj Slama² \\ ${ }^{1}$ IRSEEM (Institut de Recherche en Systèmes Electroniques Embarqués), EA 4353, \\ At the graduate school of engineering ESIGELEC, \\ Av. Galilée, BP 10024, 76801 Saint Etienne du Rouvray, France. \\ ${ }^{2}$ National Engineering School of Sousse, (ENISo), \\ Technopole de Sousse, 4054 Sousse, Tunisia. \\ Tel.: +33 (0)232915971 \\ Fax: +33(0)232915859 \\ E-mail: yang.liu@esigelec.fr, blaise.ravelo@esigelec.fr, bhslama@yahoo.fr
}

\begin{abstract}
This paper is devoted on the application of a computational method for calculating transient electromagnetic (EM) nearfield (NF) radiated by el ectronic s tructures excited b y arbitrary wave $f$ orm $p$ erturbations $i(t)$ f rom frequencydependent data. $\mathrm{T}$ he $\mathrm{m}$ ethod pr oposed is ba sed on the applications of fast Fourier tr ansform ( FFT). T he s teps illustrating the proposed method principle are described. It is based on three s uccessive s teps: the s ynchronization of the in put excitation s pectrum $I(f)$ and the gi ven frequency NF data $H_{0}(f)$, the convolution of inputs data and then, the determination of the time-domain NF emissions $H(t)$. The method feasibility is verified by simulations from EM $3 \mathrm{D}$ standard tools. In addition, a time-frequency extraction technique of the time-dependent z-transversal NF component $X_{z}(t)$ from the frequency-dependent longitudinal components $X_{x}(f)$ and $X_{y}(f)$ is also presented. This technique is $\mathrm{b}$ ased o $\mathrm{n} t$ he co njugation o $\mathrm{ft}$ he $\mathrm{p}$ lane wave spectrum (PWS) transform and FFT. Verification with NF radiated by a set of dipole radiations is made. The method introduced in this paper is particularly useful for investigating timedomain e missions f or E MC a pplications by $\mathrm{c}$ onsidering transient EM interferences (EMIs).
\end{abstract}

Keywords: Near-field (NF) emission, transient perturbations, electromagnetic compatibility (EMC), FFT, plane wave spectrum (PWS), time-frequency method, timedomain computational method.

\section{Introduction}

With $\mathrm{t}$ he unintentional e lectromagnetic interferences (EMIs), the design engineers needs to take into account the electromagnetic c ompatibility ( EMC) models during the electronic s ystems manufacture $p$ rocess [1-3]. The mo st disturbing E MC ef fects ca used b y the el ectrical/electronic system i ntegration can b e due to the E M n ear-field (NF) radiations and the couplings between the different circuits as t he el ectrical cab les and el ectronic eq uipments [4-5]. Therefore, NF emission models and scanning measurement techniques were proposed [6-9]. Nevertheless, large amount of the NF investigation were performed in f requencydomain. $\mathrm{H}$ owever, the $\mathrm{t}$ ransient perturbations a re susceptible to degrade the mixed electronic s ystems as digital a nd $\mathrm{r}$ adio $\mathrm{f}$ requencies ( RFs) [ 10] an d i ntegrated systems [11]. It has been found that the EMC engineering should include the transient EM-NF emissions especially in time-domain [10-20]. Currently, this topic attracts many of electronic engineers an $\mathrm{d} r$ esearchers. With the i ncrease of integration density and the operating rate, EM NF analysis is necessary for the RF/digital electronic boards [1-3]. Undesired transient effects can be created by different perturbations a $\mathrm{s} t$ he no n-linearity o $\mathrm{f}$ electronic devices during their commutations [10]. These transient E M-field emissions need to be canceled out for the reliability. For this reason, E M transient a nalysis is required. A s r eported in [21], analog/mixed (AM) electronic designers use regularly software $t$ ools s uch a s S PICE, while t hose working on $\mathrm{RF} /$ microwave engineering focus $\mathrm{i} \mathrm{nf}$ requency-domain simulation tools based on the S-parameters. In practice, one needs the fusion of both a pproaches as AM engineers a re required to make further analysis on the critical components by using EM simulation tools. This constitutes an improvement technique in the EMC area. In this optic, the EM emission modeling by the mixed components becomes one $\mathrm{o} f \mathrm{t}$ he cr ucial s teps $\mathrm{b}$ efore $\mathrm{t}$ he $\mathrm{i}$ mplementation. Therefore, the issues both in frequency- and time-domains should be forecasted.

Basically, the transient EM-field computation was initially determined with elementary EM dipole radiations [22-27]. As r eported in [7-8], an y el ectronic ci rcuit NF r adiations can $\mathrm{b}$ e $\mathrm{r}$ eproduced with arrays of e lementary d ipoles. Moreover, time-domain N F radiation was al so co nducted with excitation $\mathrm{b}$ ased $\mathrm{o} \mathrm{t}$ he ar bitrary wave form signals [28]. This computational approach is advantageous for the modeling of $\mathrm{E} \quad \mathrm{MN} F \mathrm{~F}$ adiated by $\mathrm{c}$ omplex electrical/electronic s tructures which cannot be modeled with most of standard tools [29-30]. This computation 
method $\mathrm{r}$ emains co mplicated when c onsidering electronic devices operating $w$ ith UWB a nd base band s ignal. So, more $\mathrm{r}$ ecently, E M c omputational method based on the plane wave spectrum (PWS) theory was proposed [31-33]. This method is based on the exploitation of the fundamental plane wave's properties and FFT, then, transposed in timedomain. I t a llows simplifying considerablyt he reconstruction of the EM NF radiations ( including the evanescent waves) as $t$ he cal culation o $f 1$ ongitudinal component ( along $\mathrm{z}$-axis) from $\mathrm{t}$ ransversal c omponents (along $\mathrm{x}$ - and $\mathrm{y}$-axes) [31-32], the NF/NF t ransform [33] and al so ex traction of the el ectric NF co mponents $\left(E_{x}, E_{y}\right.$ and $E_{z}$ ) from 2D data $H_{x}$ and $H_{y}$ [34]. In the continuation of these works, a s a special is sue of [35], the $g$ eneralized methodology of a time-frequency EM NF computation is presented in this paper.

The paper is mainly divided in three sections. Section 2 is focused on the application of the routine algorithm of EM NF time-frequency method proposed in [28][35]. Section 3 introduces a time-domain EM c omputation method based on the PWS transform for extracting EM NF component $X_{z}$ from $X_{x}$ and $X_{y}$ with a rbitrary excitations. Section 4 is the conclusion.

\section{Calculation method of time-dependent near- field maps with transient perturbations from frequency-dependent data}

This s ection d escribes th e time-frequency computation methodology presented in th is. $\mathrm{T}$ he basic theoretical approach an $d$ the $r$ outine a lgorithm are $d$ etailed. In $t$ his paper, w e will e xtend the FFT a nd I FFT i nstructions to reconstitute the time-dependent magnetic NF m aps $H_{x, y, z}(t)$ radiated $\mathrm{b}$ y an el ectronic device $\mathrm{f}$ rom $\mathrm{t}$ he frequency components $H_{x, y, z}(f)$ for any excitation undesired currents or voltages for the EMC applications as proposed in [28][35].

\subsection{Theoretical approach of the time-frequency computation method understudy}

Let us c onsider th e ti me-dependent $\mathrm{pl}$ ot of $\mathrm{t}$ he a rbitrary signal $x(t)$ presented in Figure 1. This signal is supposed as the ex citation o $\mathrm{ft}$ he electronic $\mathrm{s}$ tructure under consideration. As indicated in this figure, the sampled data corresponding $t$ o t he signal under $t$ est is $s$ upposed a nd discretized from the starting time $t_{\min }$ to the stop time $t_{\max }$ with ti me step $\Delta t$. It means that the number of $t$ imedependent samples is equal to:

$$
n=\operatorname{int}\left(\frac{t_{\max }-t_{\min }}{\Delta t}\right),
$$

with $\operatorname{int}(\alpha)$ generates the lowest integer number greater than the real number $\boldsymbol{\alpha}$.

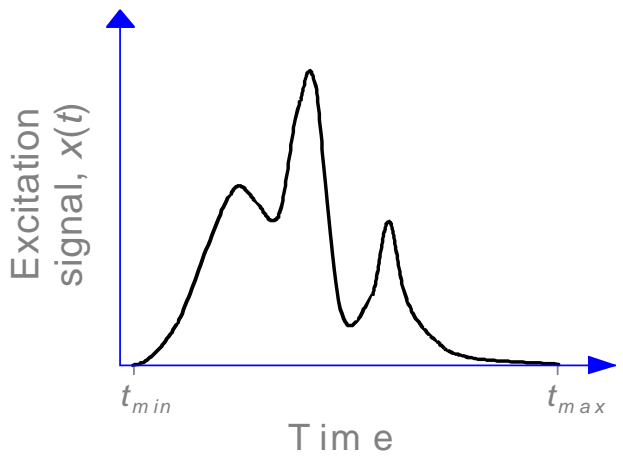

Figure 1: Transient excitation signal.

By definition, we can determine mathematically the frequency-dependent spectrum of $i(t)$ as a co mplex number denoted as:

$$
\underline{I}\left(f_{k}\right)=f f\left[i\left(t_{k}\right)\right]
$$

where $t_{k}=k \cdot \Delta t$ and $k=\{1 \cdots n\}$. In $t$ his e xpression, the variable $f_{k}$ represents th es ampling of $t$ he frequency variable. $T$ hese $f$ requencies can $b$ e ex tracted $f$ rom $t$ he sampling time parameters by the following expression:

$$
f_{k}=k \cdot \Delta f
$$

with $k=\{1 \cdots n\}$ and $\Delta f$ is the s tep f requency which i s determined by the relation:

$$
\Delta f=\frac{1}{t_{\max }-t_{\min }} .
$$

In order to operate with the excitation signal, the frequency spectrum magnitude n eeds to b e n ormalized as a co mplex coefficient. F or th is reason, $\underline{I}_{0}$ is as sumed as a h armonic component sinusoidal $\mathrm{c}$ urrent $\mathrm{n}$ ecessary for $\mathrm{g}$ enerating the electric or magnetic field spectrum $\underline{H}_{0}(f)$, the harmonics of the input cu rrent can $\mathrm{b}$ e $\mathrm{n}$ ormalized with the following complex coefficients:

$$
\underline{c}_{k}=\frac{I\left(f_{k}\right)}{\underline{I}_{0}},
$$

This normalization is illustrated by spectrum representation shown in Figure 2 [27]. 


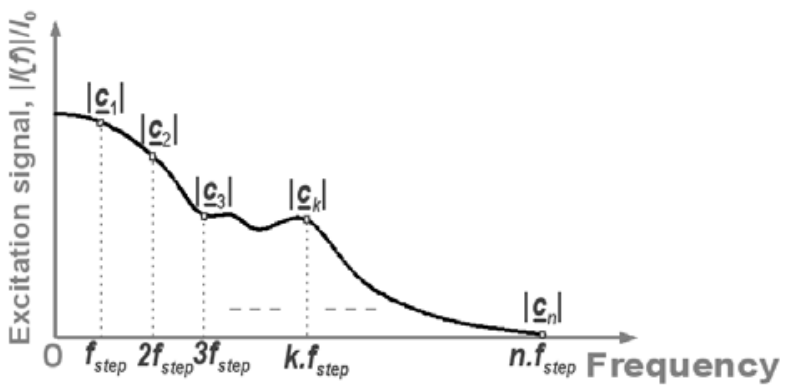

Figure 2: Extraction of the frequency spectrum coefficients from the excitation signal spectrum.

For the base band applications, it is interesting to note that the starting frequency $f_{\min }$ must b e equal to the frequency step $\Delta f$. I $\mathrm{n} \mathrm{t}$ his s cope, the s pectrum value can $\mathrm{b}$ e extrapolated linearly to generate the DC-component of the excitation signal. According to the signal processing theory, the D C-component of the ultra-short tr ansient s ignal is negligible at very low frequency band. So, the extrapolation operating will not change the calculation results. The upper frequency $f_{\max }$ must $\mathrm{b}$ elong in the frequency bandwidth containing higher t han $95 \% \mathrm{~s}$ pectrum e nergy o f the excitation signal.

Once, the frequency spectrum coefficients are defined, the time-dependent $\mathrm{N} \mathrm{F} \mathrm{d}$ ata co responding $\mathrm{t}$ o $\mathrm{t}$ he $\mathrm{t}$ ransient current signal $\mathrm{c}$ an $\mathrm{b}$ e $\mathrm{c}$ arried o ut $\mathrm{b}$ y $\mathrm{c}$ onvoluting the frequency co efficients $\underline{c}_{k}$ and the frequency-domain $\mathrm{f}$ ield data. The $r$ outine $p$ rocess will $b$ e $p$ resented in the ne $x$ subsection.

\subsection{Computational process of the proposed method}

The c omputation method developed in $t$ his $p$ aper can be summarized in $t$ wo $s$ teps. After ex tracting $t$ he frequency spectrum co efficient $\underline{c}_{k}$ from the transient e xcitation signal $i(t)$ as explained in the previous subsection, we will focus on the co nvolution $b$ etween $f$ requency s pectrum co efficients and the frequency EM field data.

Let $\mathrm{u} \mathrm{s} \mathrm{d}$ enote $\underline{H}\left(x, y, z_{0}, f\right)$ the $\mathrm{f}$ requency $\mathrm{d}$ ependent magnetic $\mathrm{f}$ ield $\mathrm{r}$ ecorded $\mathrm{i} \mathrm{nt}$ he $\mathrm{p}$ lane $z=z_{0}$ above $\mathrm{t}$ he considered $\mathrm{r}$ adiating el ectronic $\mathrm{d}$ evice as highlighted $\mathrm{b}$ y Figure 3.

The frequency EM field data $\underline{H}\left(x, y, z_{0}, f\right)$ can be obtained by $2 \mathrm{D}$ measurement $\mathrm{s}$ cans or $\mathrm{s}$ imulations with $\mathrm{s}$ tandard commercial tools.

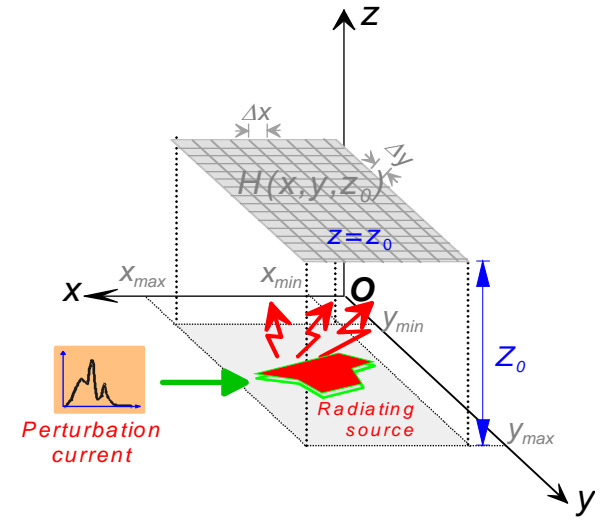

Figure 3: Representation of the magnetic NF scanned in the plane placed at the height $z_{0}$ above the radiating device.

In this case, we emphasize that the frequency EM field data $\underline{H}\left(x, y, z_{0}, f\right)$ needs $\mathrm{t}$ o b e s ynchronized with $\mathrm{t}$ he s pecific frequency interval $\left[f_{\min }, f_{\max }\right]$ of the transient excitation signal $i(t)$ a nd the frequency step $\Delta f$. A s presented i n Figure 3 , th e magnetic $\mathrm{N}$ F ti me-dependent $\mathrm{d}$ ata $\underline{H}\left(x, y, z_{0}, t\right)$ is g enerated by the d evice under t est ex cited by the current $i(t)$. As ar gued above, the magnetic NF data $\underline{H}\left(x, y, z_{0}, t\right)$ can b e d etermined with the I FFT by the convolution product of the frequency coefficient $\underline{c}_{k}$ and the frequency d ependent $\mathrm{N} \mathrm{Fd}$ ata $\underline{H}\left(x, y, z_{0}, f\right)$ via th $\mathrm{e}$ following equation:

$$
\underline{H}\left(x, y, z_{0}, t\right)=\operatorname{iff}\left[\underline{c}_{k} \cdot \underline{H}\left(x, y, z_{0}, f\right)\right],
$$

To reconstitute the ti me-domain results, the i maginary part of $\mathrm{t}$ he $\mathrm{d}$ ata $\underline{H}\left(x, y, z_{0}, t\right)$ is $\mathrm{n}$ ot $\mathrm{n}$ ecessary. T herefore, $\mathrm{t}$ he desired ti me-domain $r$ esults ar e o btained with $t$ he expression:

$$
H\left(x, y, z_{0}, t\right)=\mathfrak{R e a}\left[\underline{H}\left(x, y, z_{0}, t\right)\right],
$$

where the function $\operatorname{Real}(\boldsymbol{\alpha})$ r epresents the r eal p art of the complex num ber $\boldsymbol{\alpha}$. T he r outine process of $t$ he pr oposed computation method is presented in Figure 4 [35]. This work flow is pe rformed with di fferent ope rations i $\mathrm{n}$ or der $\mathrm{t} o$ provide th e ti me-domain $\mathrm{E} M \mathrm{~N} F \mathrm{r}$ adiated $\mathrm{b}$ y $\mathrm{t}$ he $\mathrm{d}$ evice under test with the arbitrary transient excitation signal $i(t)$.

To validate the investigated method, a $\mathrm{M}$ atlab program has been i mplemented acco rding $t$ ot he routine algorithm described in Figure 4. 


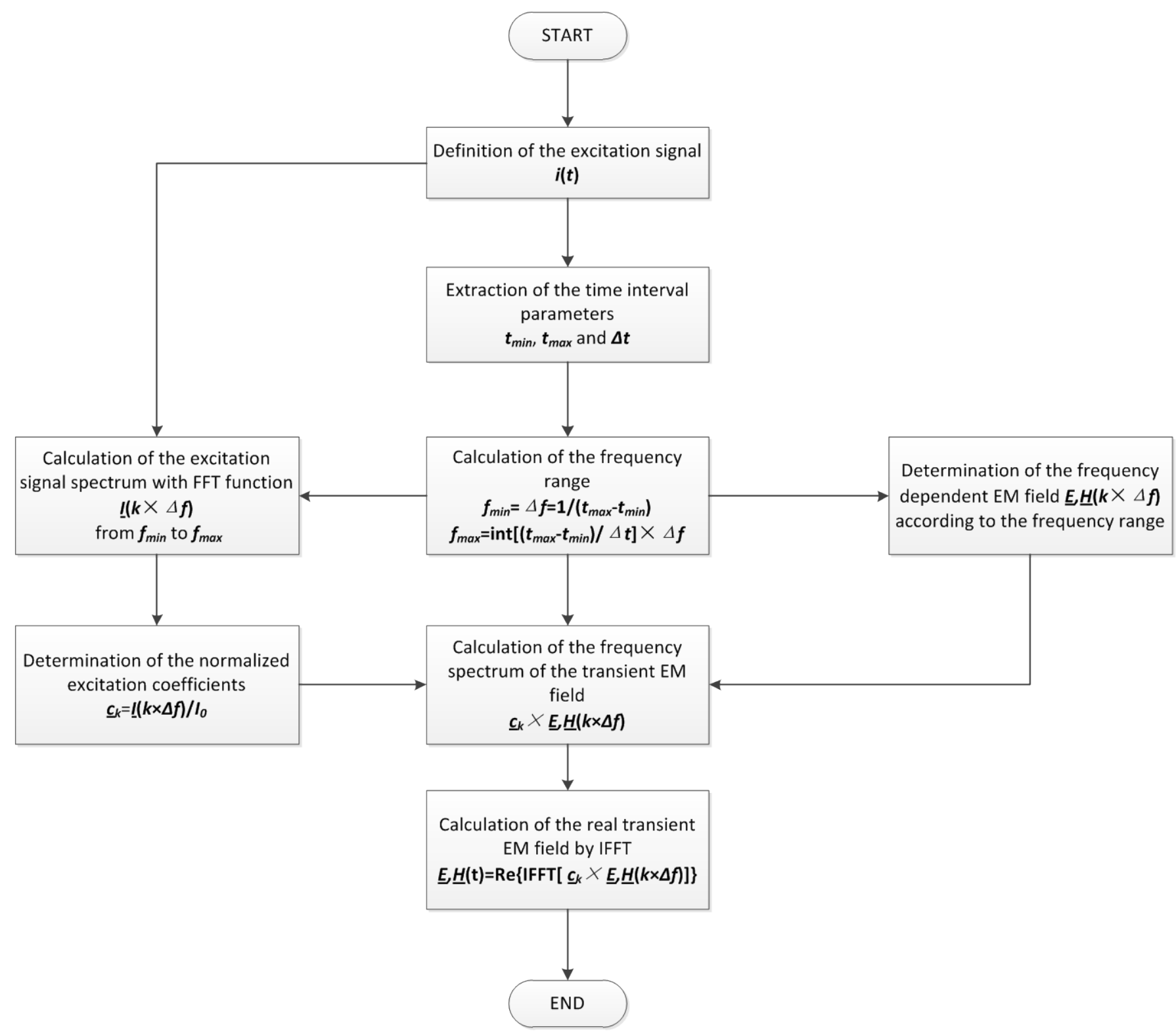

Figure 4: Routine process of the time-frequency computation method proposed [35].

\subsection{Illustration results}

In this subsection, a comparison between the transient EMfield radiated by a concrete microstrip device described from the $3 \mathrm{D}$ s oftware s imulation and $\mathrm{t}$ hose $\mathrm{o}$ btained $\mathrm{f}$ rom the proposed method is realized.

\subsubsection{Description of the Assumed Excitation Signal}

In o rder $\mathrm{t} o$ hi ghlight $\mathrm{t}$ he i nfluence o $\mathrm{ft}$ he $\mathrm{f}$ orm a nd $\mathrm{t}$ he transient variation of the disturbing currents in the electronic structure, $t$ he co nsidered s hort-duration $p$ ulse excitation current $i(t)$ is assumed as a Gaussian signal modulating 1.25 $\mathrm{GHz}$ sine carrier, defined by the analytical formula:

$$
i(t)=I_{M} \cdot \exp \left(-\frac{\left(t-t_{0}\right)^{2}}{2 \Delta t^{2}}\right) \cdot \sin \left(2 \pi f_{0} t\right),
$$

Figure $5 \mathrm{~d}$ isplays $\mathrm{r}$ espectively, $\mathrm{t}$ he tr ansient $\mathrm{p}$ lot $\mathrm{o} \mathrm{ft}$ his signal a nd its frequency s pectrum. In $\mathrm{p}$ ractice, $\mathrm{t}$ he $\mathrm{t}$ ime interval range is defined from $t_{\min }=0 \mathrm{~ns}$ to $t_{\max }=14.218 \mathrm{~ns}$ with step $\Delta t=0.1436 \mathrm{~ns}$. 

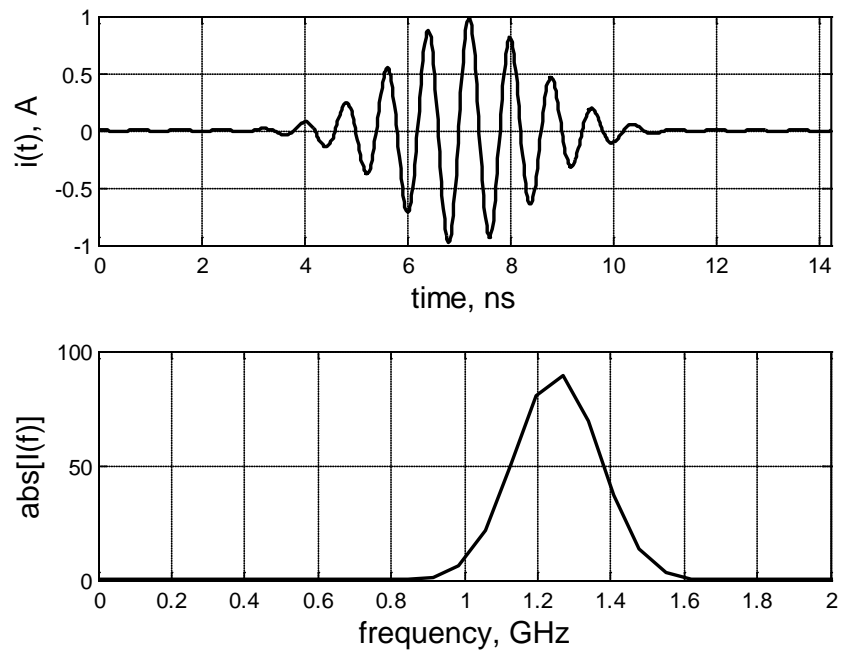

Figure 5: Transient $\mathrm{p}$ lot of the c onsidered e xcitation $\mathrm{c}$ urrent $i(t)$ and its frequency spectrum $I(f)$.

One can see that this modulated signal p resents a frequency bandwidth of $0.5 \mathrm{GHz}$, where belongs more than $95-\%$ of the spectrum s ignal e nergy. T he cal culated d ata $\underline{I}(f)=f f[i(t)]$ implies the frequency coefficient $v$ alues of $i(t)$ acco rding to the $d$ efinition e xpressed in ( 8) as described ea rlier in subsection 2.2.

\subsubsection{Description of the device under test}

The microstrip circular resonator shown i $\mathrm{n} \mathrm{F}$ igure 6 was designed and considered as the device under test in order to validate the method under i nvestigation. $\mathrm{T}$ he $\mathrm{r}$ esonator i $\mathrm{s}$ based on a substrate with relative permittivity $\varepsilon=10$. It is fed by the via hole port with the transient current presented above. The top view of the resonator is shown by Figure 6 .

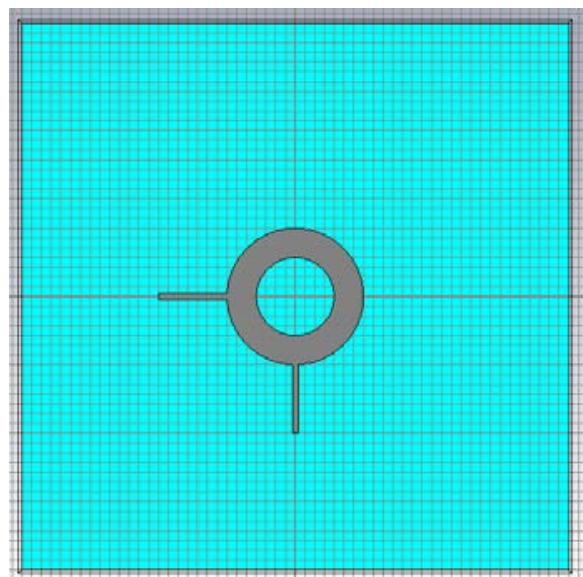

Figure 6: Top view of the microstrip circular resonator.

To validate the method proposed in this paper, comparisons of different $r$ esults were made $b$ etween $t$ he $\mathrm{C}$ ST M icrowave simulations and the computation method proposed.

\subsubsection{Transient EM-Field Determined by CST MWS simulation}

By c onsidering the circular $r$ esonator $\mathrm{p}$ resented in Figure 6 , excited $\mathrm{b}$ y th e $\mathrm{p}$ ulse $\mathrm{c}$ urrent $\mathrm{p}$ lotted in $\mathrm{F}$ igure $5 \mathrm{y}$ ields $\mathrm{t}$ he electric and magnetic field components mappings depicted in Figure 7 and Figure 8 at the arbitrary time $t_{0}=7.611 \mathrm{~ns}$ and in the horizontal plan parallel to $(O x y)$ referenced by $z_{0}=2 \mathrm{~mm}$. The dimensions of the mappings were set at $L_{x}=56 \mathrm{~m} \mathrm{~m}$ and $L_{y}=56 \mathrm{~mm}$ with resolutions respectively, equal to $\Delta x=1 \mathrm{~mm}$ and $\Delta y=1 \mathrm{~mm}$.
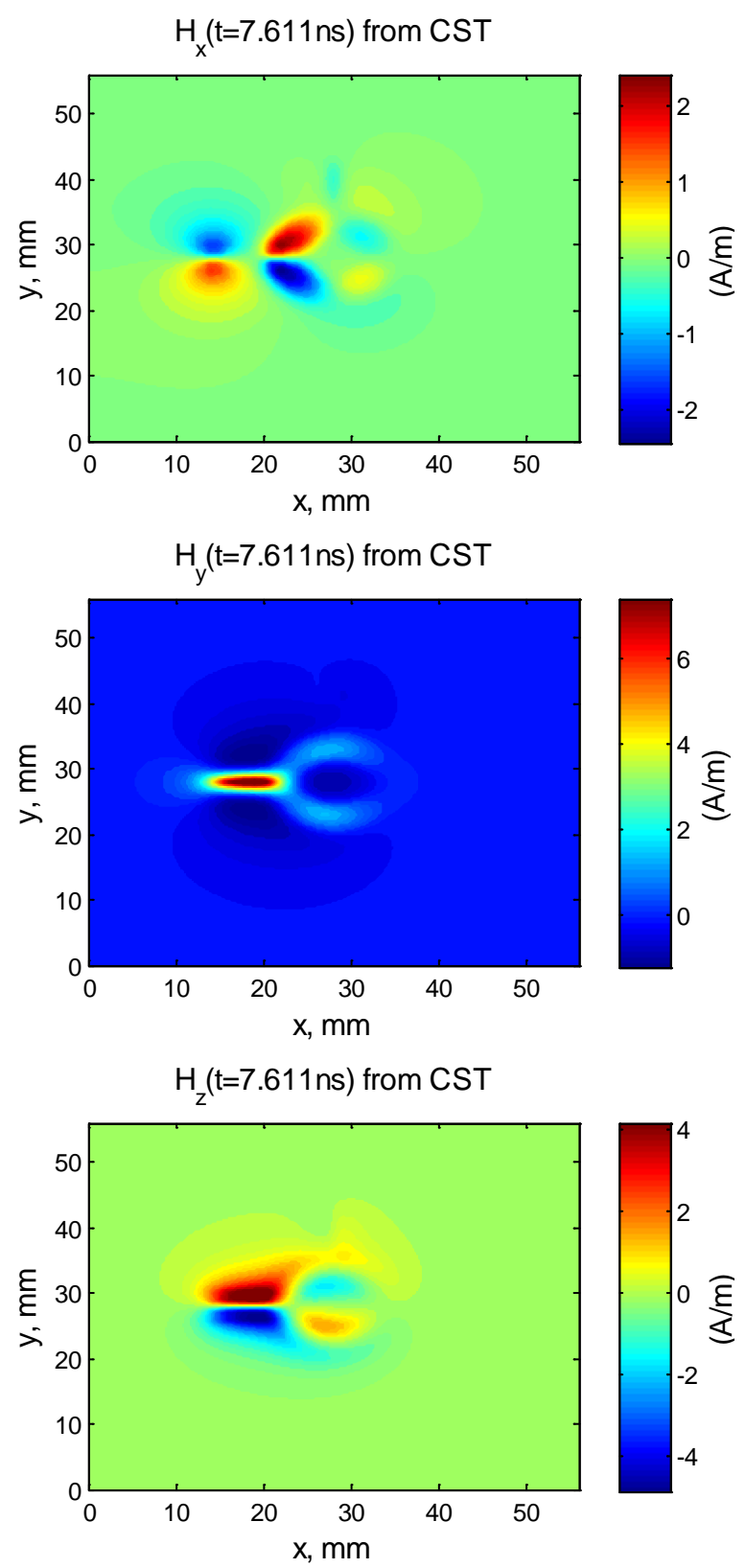

Figure 7: Cartographies of magnetic field components at $t=7.611$ ns obtained from the CST simulation. 
$E_{x}(t=7.611 n s)$ from CST

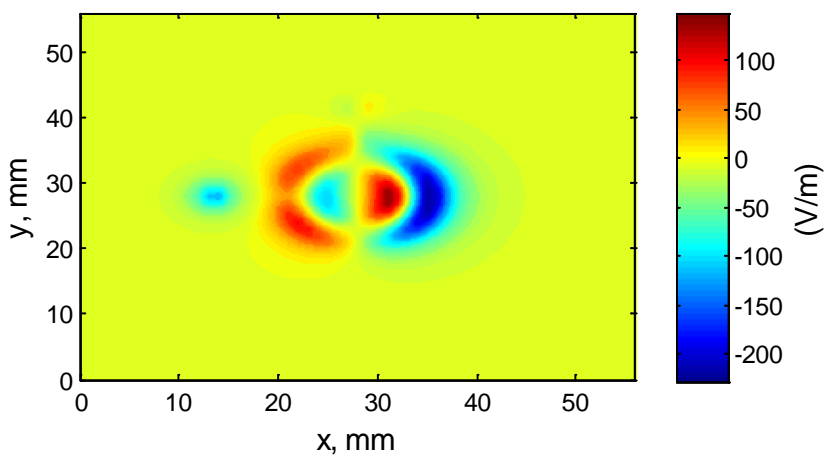

$E_{y}(t=7.611 n s)$ from CST

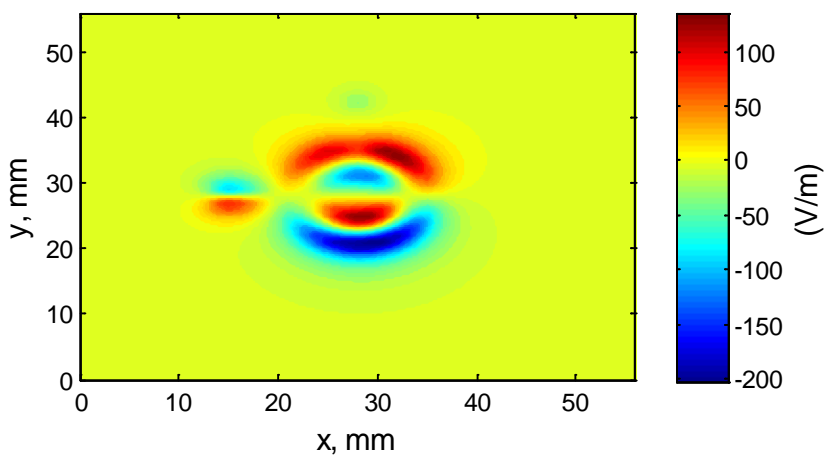

$E_{z}(t=7.611 n s)$ from CST

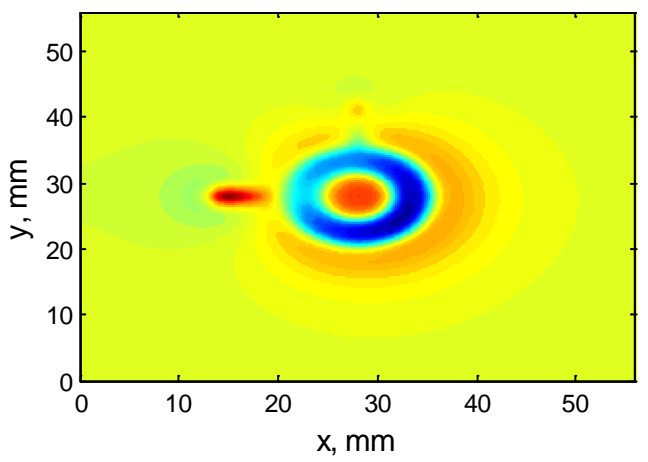

Figure $8: \mathrm{C}$ artographies o $\mathrm{fe}$ lectric $\mathrm{f}$ ield components at $t=7.611 \mathrm{~ns}$ obtained from the CST simulation.

\subsubsection{Computed Results from the Proposed Method}

First, by analyzing the frequency-domain results a chieved by CST Microwave Studio, one obtains the cartographies of the frequency-dependent electric and magnetic field from $f_{\min }=1$ $\mathrm{GHz}$ to $f_{\max }=1.5 \mathrm{GHz}$ step $\Delta f=0.01 \mathrm{GHz}$.

After the program execution of the algorithm indicated by the flow chart described by Figure 4, one gets the results shown in Figure 9 and Figure 10 via the combination of the frequencydependent $d$ ata of the el ectric or magnetic field components associated to the frequency coefficient of the excitation signal. One can see that one establishes the cartographies having the same behaviors as those generated via the direct calculations displayed in Figure 7 and Figure 8.
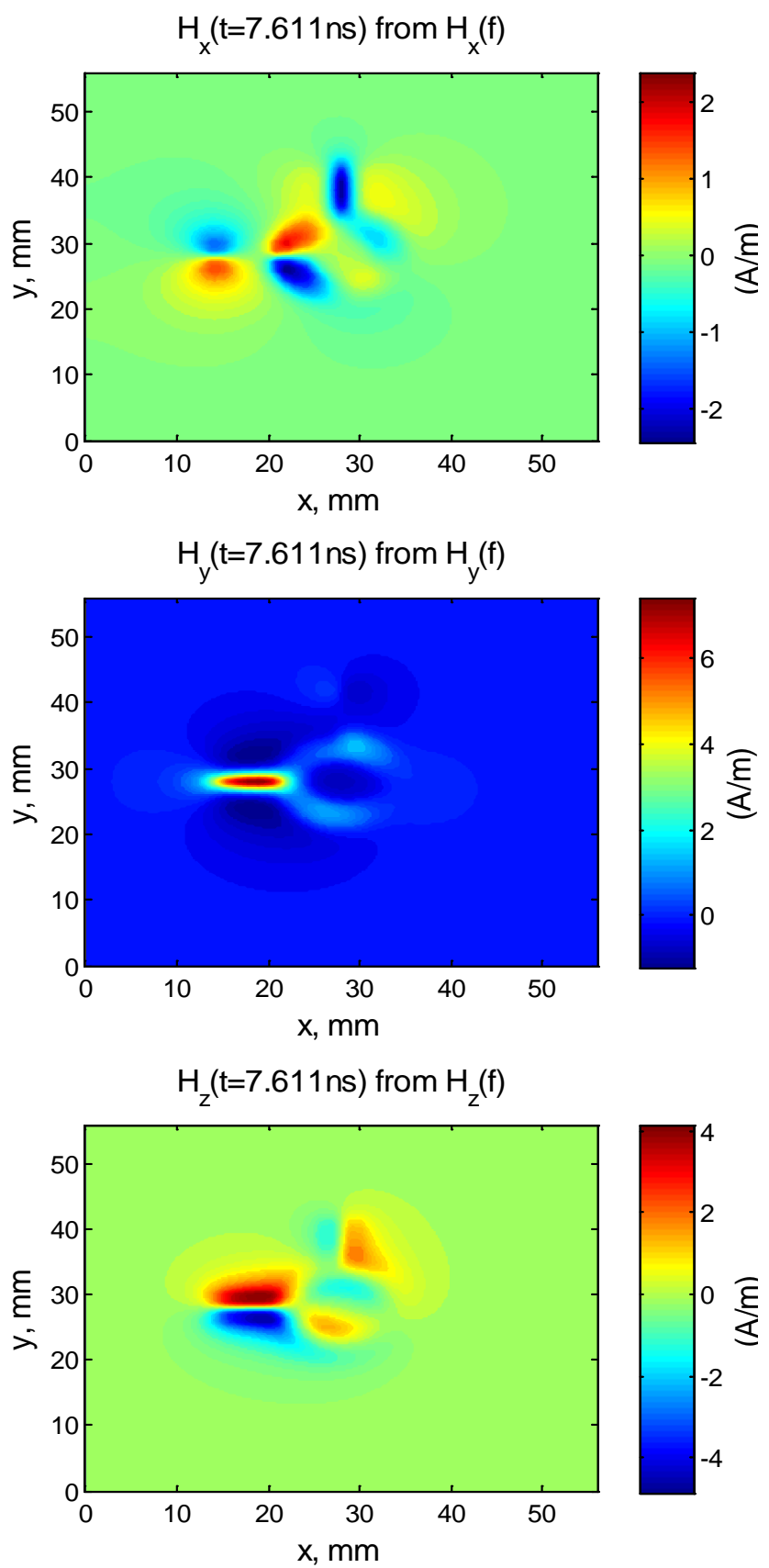

Figure 9: $\mathrm{C}$ artographies o $\mathrm{f}$ magnetic $\mathrm{f}$ ield components: obtained $\mathrm{f}$ rom $\mathrm{t}$ he pr oposed $\mathrm{t}$ ime-frequency c omputation method. 

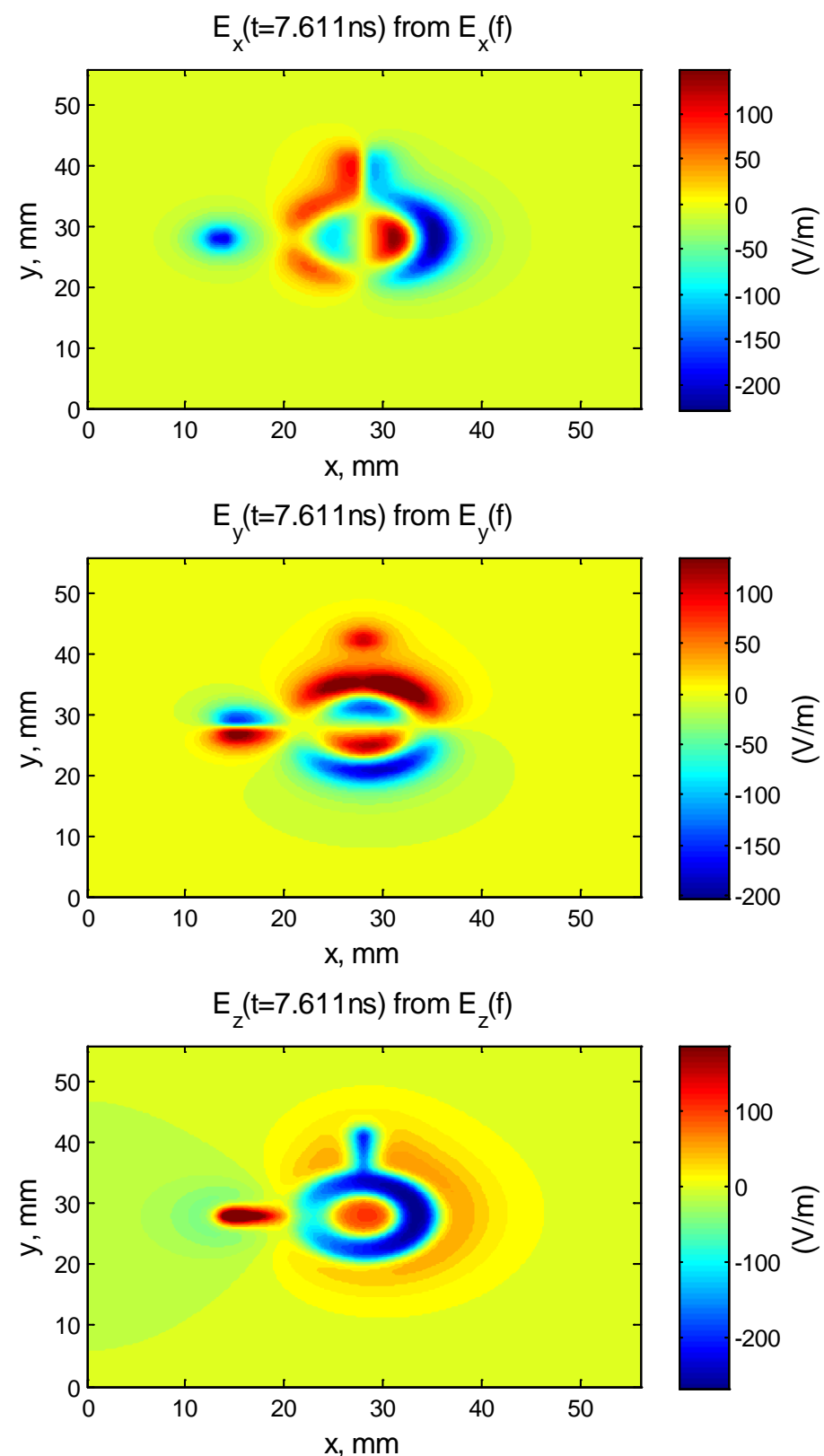

Figure 10: $\mathrm{C}$ artographies of electric $\mathrm{f}$ ield components: obtained $\mathrm{f}$ rom $\mathrm{t}$ he $\mathrm{pr}$ oposed $\mathrm{t}$ ime-frequency c omputation method.

Furthermore, as illustrated by Figure 11 and Figure 12, a very good correlation be tween the profiles along $O x$ ar $O y$ of the EM field components detected in the vertical plane placed at $x$ $=22 \mathrm{~mm}$ or $y=30.3 \mathrm{~mm}$ was observed.
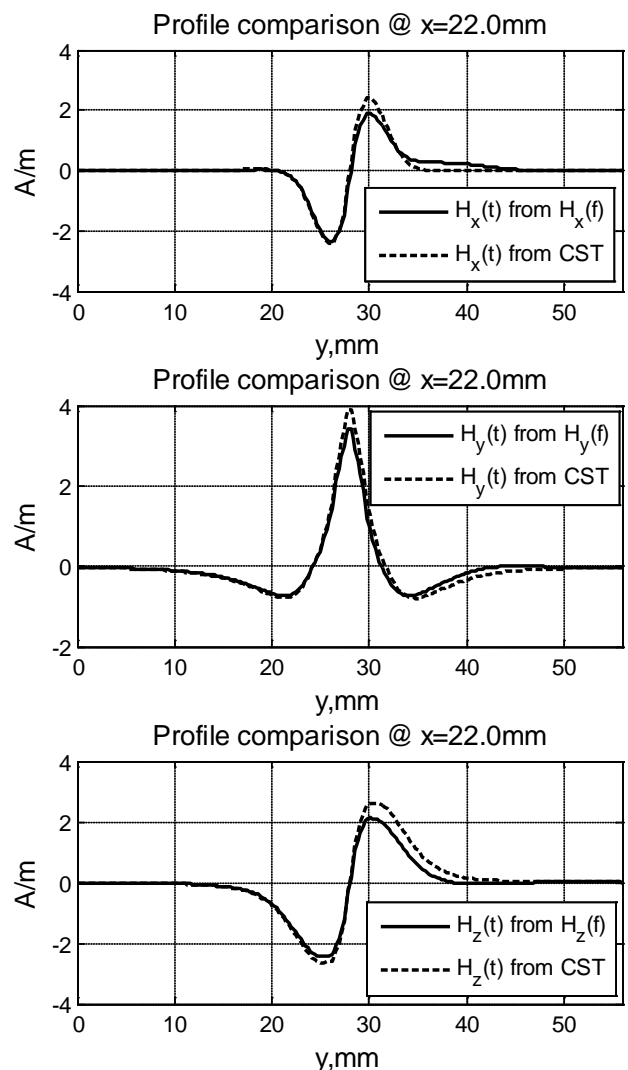

Figure 11: $\mathrm{C}$ omparisons of $\mathrm{t}$ he magnetic $\mathrm{f}$ ield components profiles obt ained $\mathrm{f}$ rom $\mathrm{t}$ he pr oposed tim e-frequency computation method and the direct calculation, detected in the vertical plane $x=22 \mathrm{~mm}$.
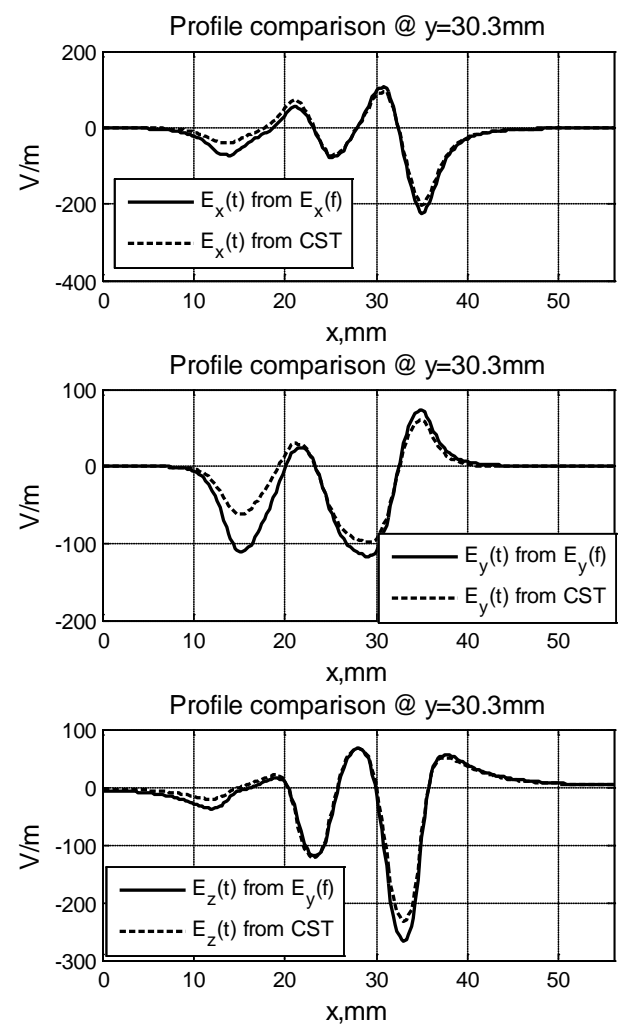
Figure 12: Co mparisons of the electric field components profiles obt ained $f$ rom $t$ he pr oposed $t$ ime-frequency computation method and the direct calculation, detected in the vertical plane placed at $y=30.3 \mathrm{~mm}$.

In addition to this c omputation method, we propose further method e nabling $\mathrm{t}$ o e xtract $\mathrm{t}$ he $\mathrm{t}$ hird $\mathrm{c}$ omponent ( along $\mathrm{z}$ direction) of EM fields in time-domain knowing the two first components (along $\mathrm{x}$ - and $\mathrm{y}$ - directions) in the next section.

\section{Extraction method of the transverse component $X_{z}(t)$ from $X_{x}(f)$ and $X_{y}(f)$ with ultra-short duration transient perturbations}

To reduce the order of complexity and the processing time of measurement, we propose a method to ex tract the time EM transversal component $X_{z}(t)$ from the known the longitudinal components $X_{x}(t)$ and $X_{y}(t)$. To do this, we use the Plane Wave Spectrum ( PWS) method associated with th e $r$ adiation of electric dipoles in the time domain as introduced recently in [31-32].

The $\mathrm{b}$ asic ap proach o $\mathrm{fE} \mathrm{Mf}$ ield $\mathrm{c}$ haracterization in $\mathrm{t}$ ime domain i s ex tracted f rom $t$ he f requency $d$ ata co mbined via FFT. First, the PWS theory which was initially introduced in [36-38] w ill be a pplied t o t he obt ained da ta i $\mathrm{n}$ frequency domain. F inally, the frequency $d$ ata will $b$ e transposed in to time domain with IFFT.

3.1. Principle of the time-frequency method of the $z$ component calculation from $x$-/y-components of the EM NF

By d efinition, th e P WS m ethod [31-33][36-38] is a b asic method de dicated to th e d ecomposition o f a ny E M-field plotted in $2 \mathrm{D}$ as a sum of plane waves propagating in different space directions. One denotes:

$$
\vec{k}=k_{x} \overrightarrow{u_{x}}+k_{y} \overrightarrow{u_{y}}+k_{z} \overrightarrow{u_{z}},
$$

the wave vector in the rectangular co ordinate s ystem (Oxyz) with unit vectors, $\overrightarrow{u_{x}}, \overrightarrow{u_{y}}$ and $\overrightarrow{u_{z}}$. The modulus of this wave vector, what is also known as the wave number, is given by:

$k(f)=\sqrt{k_{x}^{2}(f)+k_{y}^{2}(f)+k_{z}^{2}(f)}=\frac{2 \pi}{\lambda(f)}=\frac{2 \pi f}{v}$. where $\lambda(f)$ is the wavelength at the operating f requency $f$. According to the PWS theory, the EM field $\vec{X}(x, y, z)$ can be expressed as a d ouble i ntegral o $\mathrm{ft}$ heir $\mathrm{P}$ WS co mponents $\vec{P}_{X}\left(k_{x}, k_{y}, z\right)$ with the following formulation:

$$
\vec{X}(x, y, z)=\frac{1}{4 \pi^{2}} \int_{-\infty}^{\infty} \int_{-\infty}^{\infty} \vec{P}_{X}\left(k_{x}, k_{y}, z\right) e^{j\left(k_{x} x+k_{y} y\right)} d k_{x} d k_{y}
$$

Similar to the 2D Fourier transform, the inverse PWS (IPWS) of EM field is given by the following equation:

$$
\overrightarrow{P_{X}}\left(k_{x}, k_{y}, z\right)=\int_{-\infty}^{\infty} \int_{-\infty}^{\infty}[\vec{X}(x, y, z)] e^{-j\left(k_{x} x+k_{y} y\right)} d x d y,
$$

The ho rizontal $X-Y$ plane is with di mensions $L_{x} \times L_{y}$. It is discretized with the steps $\Delta x$ and $\Delta y$, respectively, so that the discrete indexes, $n_{x}$ and $n_{y}$ are:

$$
\begin{aligned}
& k_{x}=\frac{2 \pi}{x}=\frac{2 \pi}{n_{x} \Delta x}, \\
& k_{y}=\frac{2 \pi}{y}=\frac{2 \pi}{n_{y} \Delta y} .
\end{aligned}
$$

In this case, the horizontal components of the wave vector $k_{x}$ and $k_{y}$ vary respectively between:

$$
\begin{aligned}
& k_{x \min }=-\frac{\pi}{\Delta x}, \\
& k_{y \text { min }}=-\frac{\pi}{\Delta y},
\end{aligned}
$$

and

$$
\begin{aligned}
& k_{x \max }=\frac{\pi}{\Delta x}, \\
& k_{y \max }=\frac{\pi}{\Delta y},
\end{aligned}
$$


with the numerical step:

$$
\begin{gathered}
\Delta k_{x}=\frac{2 \pi}{L_{x}}, \\
\Delta k_{y}=\frac{2 \pi}{L_{y}} .
\end{gathered}
$$

From e quation (10), one ca $\mathrm{n} d$ etermine $\mathrm{t}$ he co rresponding vertical component [31-33][36-38]:

$$
k_{z}=\left\{\begin{array}{c}
\sqrt{k^{2}-k_{x}^{2}-k_{y}^{2}} \text { if } k_{x}^{2}+k_{y}^{2}<k^{2} \\
-j \sqrt{k_{x}^{2}+k_{y}^{2}-k^{2}} \text { if } k_{x}^{2}+k_{y}^{2}>k^{2}
\end{array} .\right.
$$

To avoid the unexpected case, the following relation must be respected.

$$
\max \left(\Delta k_{x}, \Delta k_{y}\right)<\frac{2 \pi}{\lambda}
$$

And also, at the boundary condition, the field components and their PWS components, $X_{x, y, z}$ and $P_{X_{x, y}}$ must tend to zero. According to the plane wave properties, wave vectors $\vec{k}$ and $\vec{P}$ must be perpendicular to each other:

$$
\vec{k} \cdot \vec{P}_{X}=0 \Rightarrow k_{X} P_{X_{X}}+k_{y} P_{X_{y}}+k_{z} P_{X_{z}}=0
$$

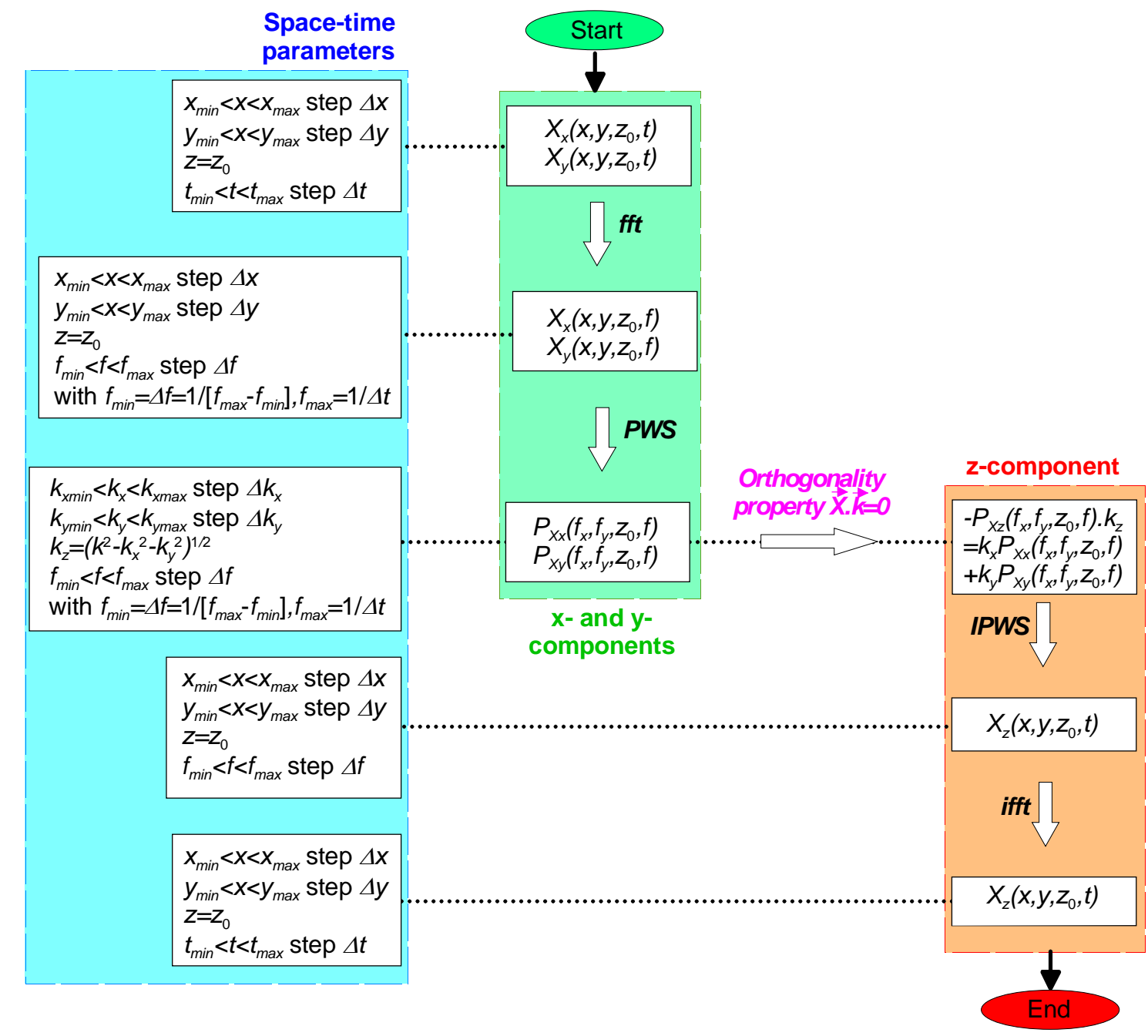

Figure 13: Routine algorithm illustrating the computation method of $X_{z}$ from $X_{x}$ and $X_{y}$ by using the PWS transform. 
So that, the vertical component $P_{X_{z}}$ can be determined by the following equation:

$$
P_{X_{z}}=-\frac{k_{x} P_{X_{x}}+k_{y} P_{X_{y}}}{k_{z}} .
$$

All the approaches and calculations presented above work in the $f$ requency $d$ omain. So, we need to transform th e ti me domain data $X_{x}(t)$ and $X_{y}(t)$ into frequency d omain b y using the Fourier transform $X_{x, y}(f)=f f t\left[X_{x, y}(t)\right]$. Also, at the end of this $\mathrm{p}$ rocedure, the $\mathrm{z}$-component $X_{\mathrm{z}}(f)$ must b e $\mathrm{t}$ ransform back i nto time d omain by the i nverse Fourier transform $X_{z}(t)=i f f\left[X_{z}(f)\right] . \mathrm{F}$ igure $11 \mathrm{~s}$ ummarizes $\mathrm{t}$ he $\mathrm{r}$ outine algorithm of the method proposed.

As a co nclusion, al $1 \mathrm{t}$ he $\mathrm{p}$ rocedure ab ove means that $P_{X_{z}}$, obviously $X_{z}$, can be extracted from $P_{X_{x}}$ and $P_{X_{y}}$ which can be calculated from the IPWS equation expressed in (12) if the 2D data $X_{x}$ and $X_{y}$ are given. In summary, with the proposed method, the EM NF measurement processes can be simplified.

\subsection{Application results}

To validate the computation method proposed in this paper, a set of elementary electric dipoles with arbitrarily chosen configuration is placed in the $\mathrm{X}-\mathrm{Y}$ plane as displayed in Figure 14. It is considered as a radiating source defined by analytical equations proposed in [39-41]. All th e e lectric d ipoles a re simultaneously excited by the same time varying current $I(t)$. Figure 15 displays th e c urrent e xcitation. The $\mathrm{f}$ requency spectrum of $I(t)$ plotted in F igure 16 presents a maximum frequency of about $5 \mathrm{GHz}$.

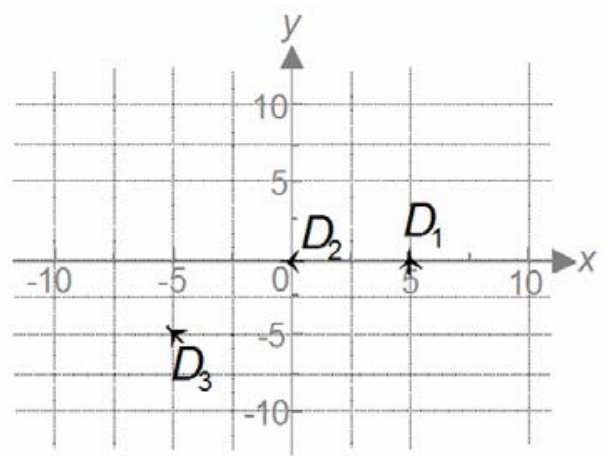

Figure 14: Assumed configuration of the set of three el ectric dipoles.
So, th e minimum wave le ngth is $\lambda_{\min }=c / f_{\max }=0.6 \mathrm{~m}$. According to the wave propagation theory, the NF zone is up to about $\lambda_{\text {min }} / 10=6 \mathrm{~cm}$ above the dipoles plane.

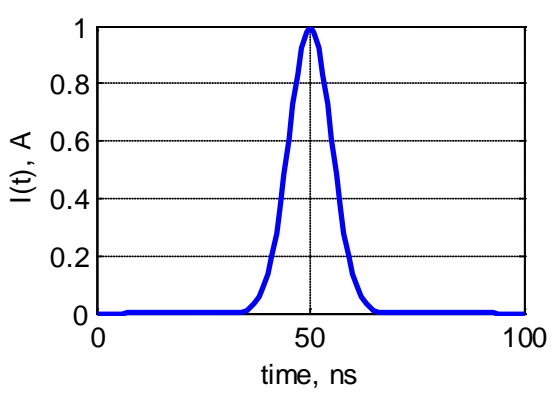

Figure 15: Time variation of the excitation signal.

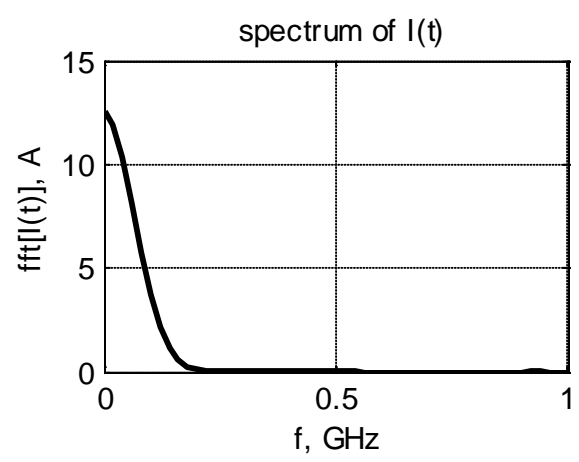

Figure 16: Frequency spectrum of the excitation signal $I(t)$ shown in Figure 15.

First, w e w ill calculate the tr ansient e lectric fields with formulae expressed in [39-40]. $T$ he results are shown in Figure 17, the plots plane is at the height $z=10 \mathrm{~mm}$ and at the time $t_{0}=50 \mathrm{~ns}$. The profile of the Electric field along the line equated b y $x=0 \mathrm{~mm}$ is shown b y $\mathrm{F}$ igure 18 . The three transient el ectric field co mponents ar e o btained at the three different point in the plane $z=10 \mathrm{~mm}$, shown as Figure 19.

Second, the vertical electric field component $E_{z}(t)$ extracted by the P WS m ethod $w$ ill be co mpared $w$ ith the own $E_{z}(t)$ calculated directly. T his co mparison is s hown by Figure 19. The comparison of the $E_{z}$ distribution at $t=50 \mathrm{~ns}$ a cross the horizontal plane at $\mathrm{z}=10 \mathrm{~mm}$, is shown in Figure 20 . One can s ee a good ag reement in the zone w ith hi gher $\mathrm{f}$ ield strengths with almost the same distribution. 

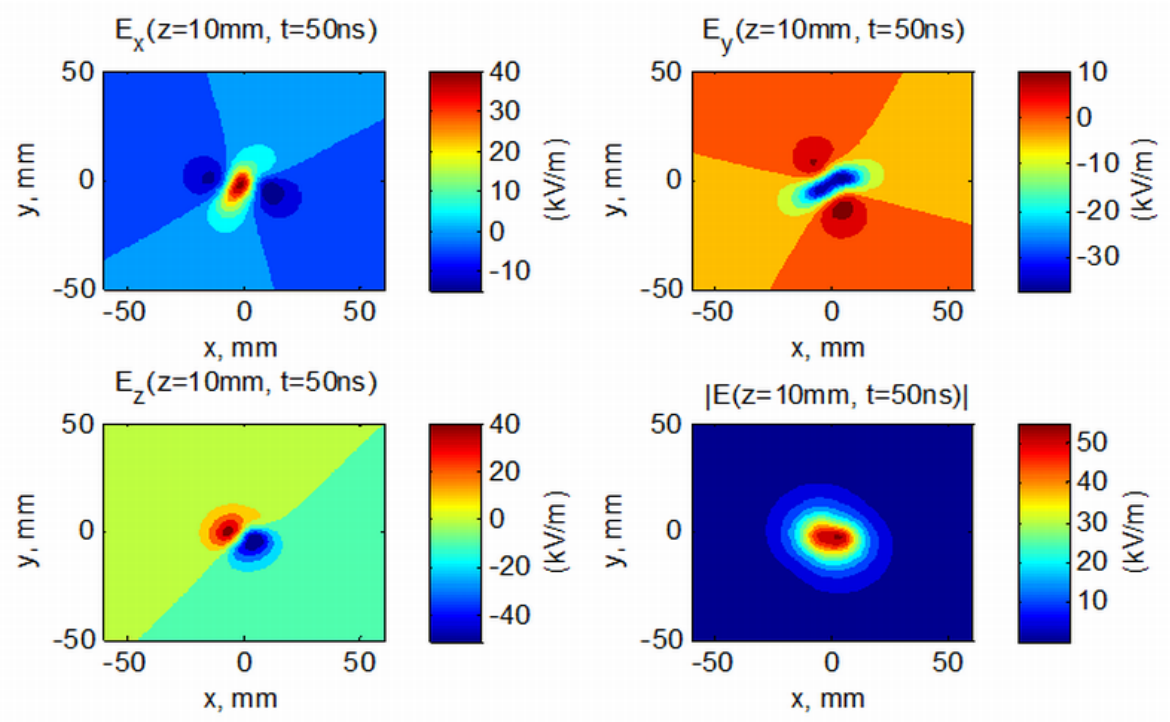

Figure 17: Calculated electric field components $E_{x}, E_{y}$ and $E_{z}$ and the total magnitude $|E|$ for the dipoles in Figure 14 at the horizontal plane at the height $z=10 \mathrm{~mm}$ at the instant time $t=50 \mathrm{~ns}$.

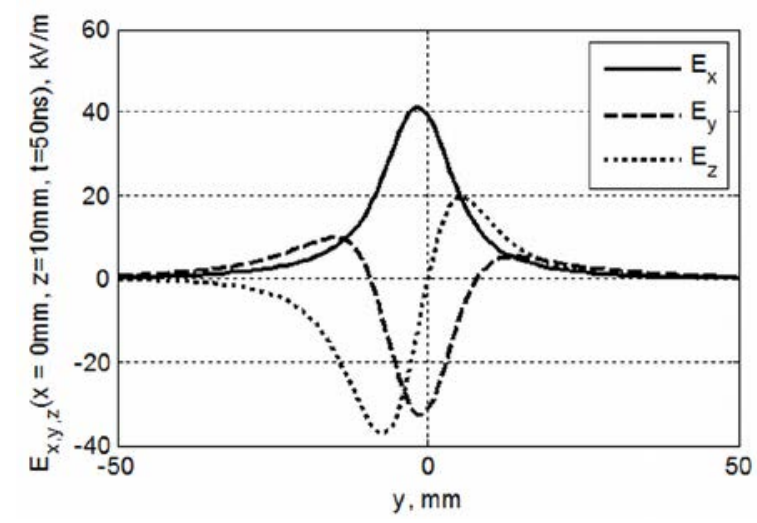

Figure 18: Calculated electric field components $E_{x}, E_{y}$ and $E_{z}$ for the dipoles in Figure 14 along the line $z=10 \mathrm{~mm}, x=0$ and at the instant time $t=50 \mathrm{~ns}$.
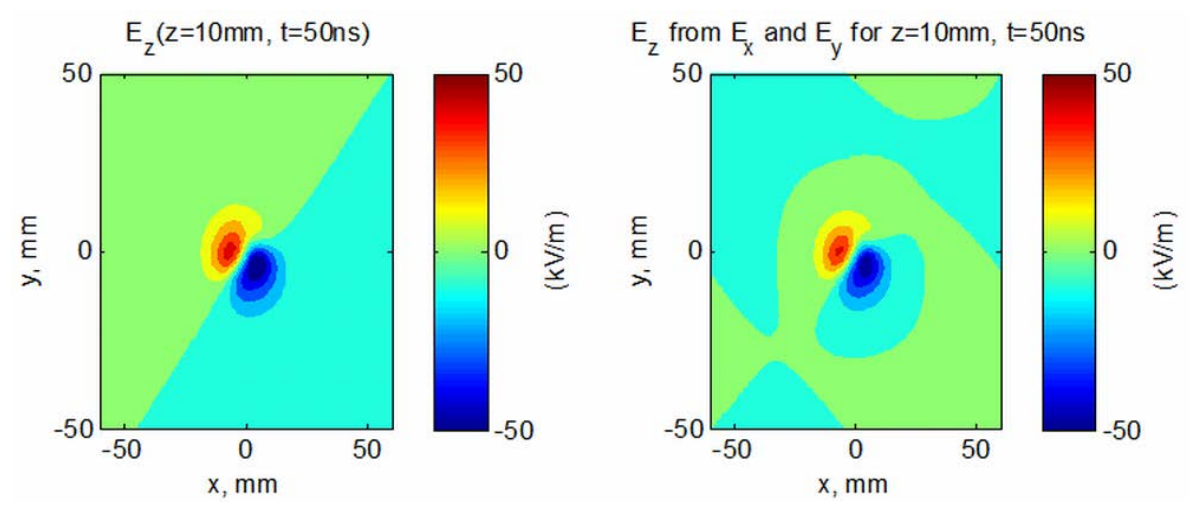

Figure 19: Comparison between the $E_{z}$ components directly computed and ex tracted at the instant time $t=50$ ns across the horizontal plane at $z=10 \mathrm{~mm}$. 


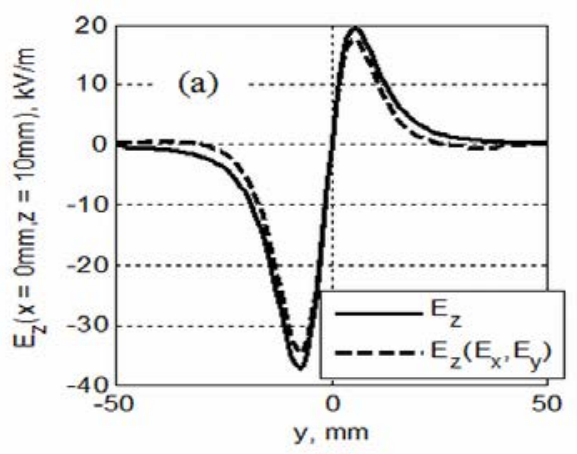

(a)

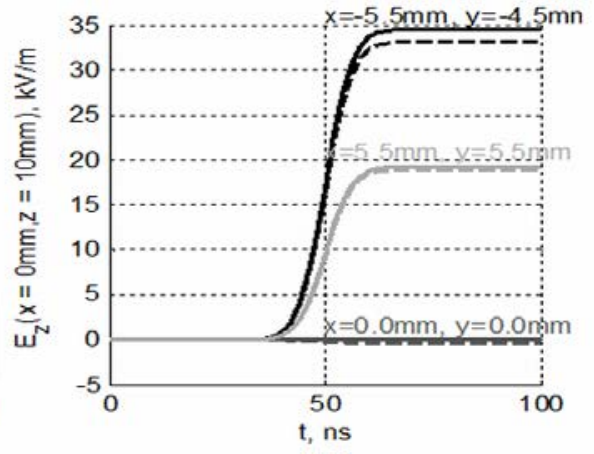

(b)

Figure 20: Comparison between directly computed and extracted $\mathrm{E}_{\mathrm{z}}$ field: (a) at the instant time $t=50 \mathrm{~ns}$ along the line $z=10$ $\mathrm{mm}, x=0$; (b) as a function of time at the points $(x, y)=\{(0,0),(-5.5 \mathrm{~mm},-4.5 \mathrm{~mm}),(5.5 \mathrm{~mm}, 4.5 \mathrm{~mm})\}$ on the horizontal plane at $z=10 \mathrm{~mm}$.

We can also find some errors in the zone with lower field strengths. However, these er rors ar e r elatively s mall. They can be visualised in Figure 20. We can see that the relative errors are very small at the randomly chosen points.

In order to verify the relevance of the proposed method, we also simulate the transient radiation of the set of dipoles in Figure 14 with commercial 3D EM modelling software, CST Microwave $\mathrm{S}$ tudio ${ }^{\mathrm{TM}}$. Figure 21 describes the s etup of the electric dipoles in CST MWS simulation.

The results of simulations with CST MWS are displayed in Figures 22.

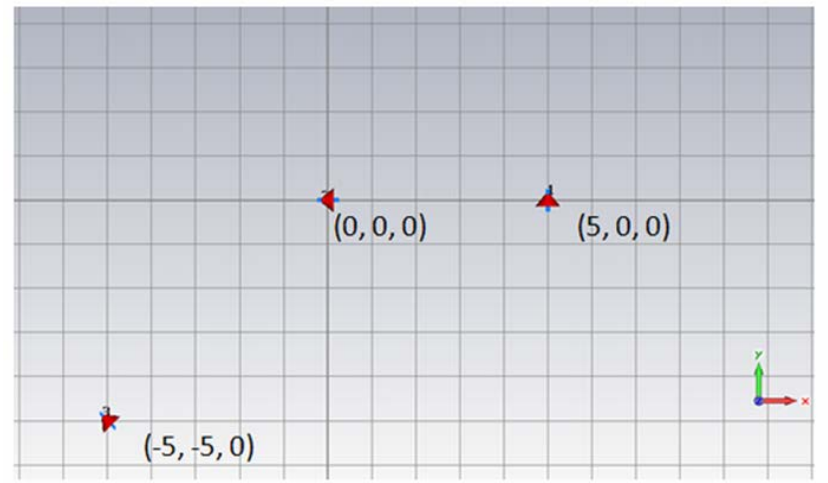

Figure 21: CST MWS simulation setup for the three dipoles from Figure 14.

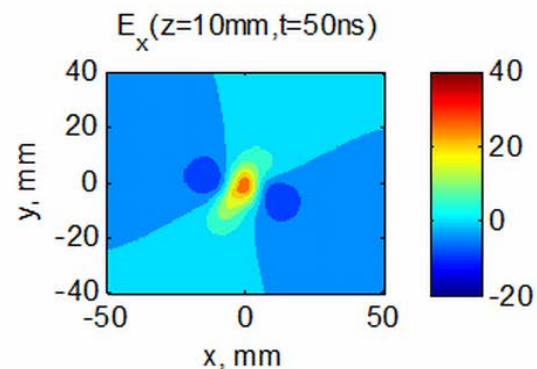

$E_{z}(z=10 \mathrm{~mm}, \mathrm{t}=50 \mathrm{~ns})$ from CST

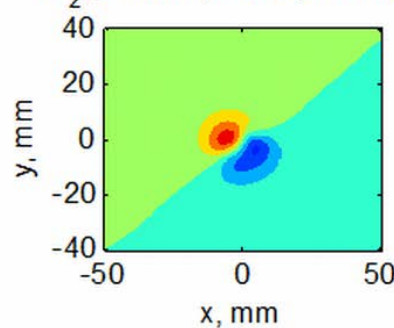

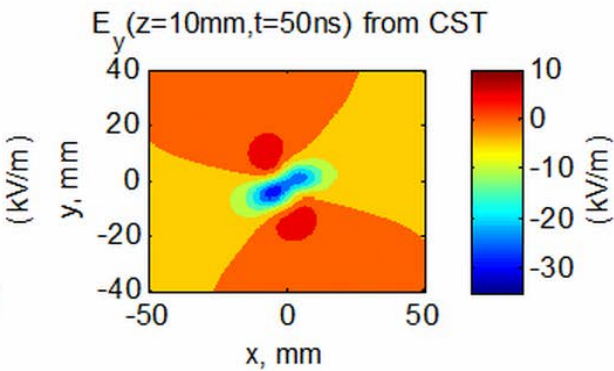

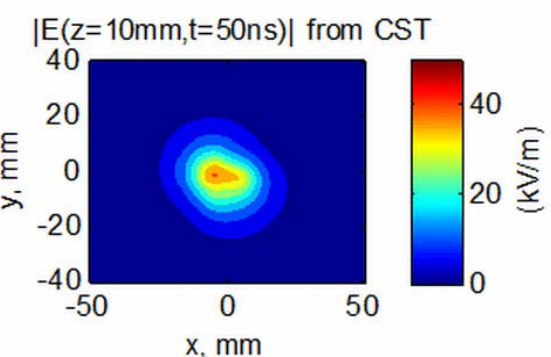


Figure 22: Simulated electric field components $E_{x}, E_{y}$ and $E_{z}$ and the total magnitude $|E|$ for the dipoles in Figure 14 at the horizontal plane at the height $\mathrm{z}=10 \mathrm{~mm}$ at the instant time $t=50 \mathrm{~ns}$.

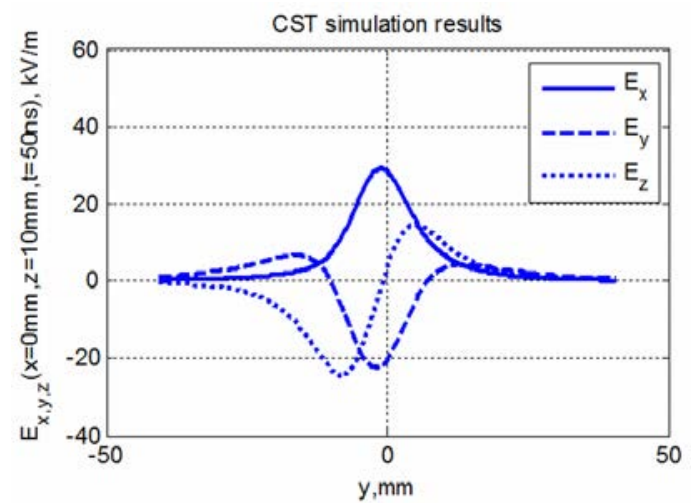

Figure 23: Simulated electric field components $E_{x}, E_{y}$ and $E_{z}$ for the dipoles in Figure 21 along the line $z=10 \mathrm{~mm}$ and $x=0$ and at the instant time $t=50 \mathrm{~ns}$.

Through these figures, we can see that the simulations and calculation $r$ esults present a $\mathrm{v}$ ery g ood co rrelation. $\mathrm{T}$ he almost same field distributions are found. However, we can find some differences in the magnitude, when we compare the simulation and calculation results. These differences can be co nsidered as $t$ he $p$ roblem o $\mathrm{ft}$ he mesh s izes of the considered EM simulator.

\section{Conclusions}

The methodology of time-frequency EM NF computation is successfully de veloped in this paper. The method proposed consists mainly in c onvoluting the E M N F o btained from frequency calculation, simulations or measurements in wide frequency $b$ and a nd a ny $t$ ransient a rbitrary wave $f$ orm perturbations.

In the first part of the paper, theoretical approach illustrating the $r$ outine a lgorithm of $t$ he method is e stablished. Then, application by comparing simulations of a microwave device with a standard co mmercial t ool an $\mathrm{d} s$ emi-analytical calculations $\mathrm{r}$ un in $\mathrm{M}$ atlab $\mathrm{p}$ rogramming e nvironment was made $t o$ ve rify $t$ he va lidity of $t$ he method. $T$ o do $t$ his, a transient current with pulse wave form presenting s ome n $\mathrm{s}$ time-duration was co nsidered. A s ex cepted a ood correlation with $\mathrm{r}$ esults $\mathrm{f}$ rom a nalytical $\mathrm{c}$ alculation $\mathrm{w}$ as found.

In $t$ he $s$ econd pa rt of the pa per, a $t$ ransposition of a frequency method based on the PWS spectrum is presented.
The flow ch art summarizing the co mputation of EM wave component $\mathrm{X}_{\mathrm{z}}$ from $\mathrm{X}_{\mathrm{x}}$ and $\mathrm{X}_{\mathrm{y}}$ in $2 \mathrm{D}$ i s e xplained. Then, application with the radiation of set of EM dipoles is presented. Once ag ain, as expected a v ery good correlation with ti me-domain $r$ esults $f$ rom a 3 D E M s imulation commercial tool is performed.

The approach introduced in this paper can be very useful for time domain EM near field modeling and characterization in EMC a pplication. The $\mathrm{m}$ ethod es tablished i s cu rrently extended for the modeling of EM NF emissions based on the set of elementary dipoles [41] based on the frequency models developed in [7-8].

\section{Acknowledgements}

Acknowledgement is made t o E uropean U nion ( EU) a nd Upper Normandy region (FRANCE) for the support of this research through the European INTERREG IVA project No 4081 e ntitled " Time-Domain E lectromagnetic Characterization and Simulation (TECS)".

\section{References}

[1] T. Yang, Y. B ayram a nd J. L . V olakis, “ Hybrid Analysis o fE lectromagnetic I nterference E ffects o $n$ Microwave A ctive C ircuits Within C avity E nclosures," IEEE Trans. EMC, V ol. 52, No. 3, pp. 74 5-748, A ug. 2010.

[2] B. Archambeault, C. B rench and S. Connor, "Review of $\mathrm{P}$ rinted-Circuit-Board L evel E MI/EMC I ssues an d 
Tools," IEEE Trans. EMC, Vol. 52, No. 2, pp. 455-461, May 2010.

[3] P.-A. Barriere, J.-J. Laurin and Y. Goussard, "Mapping of E quivalent Currents o $\mathrm{H}$ H igh-Speed D igital P rinted Circuit B oards B ased o n N ear-Field M easurements," IEEE Trans. EMC, Vol. 51, No. 3, pp. 649 - 658, Aug. 2009.

[4] E. R . R ajkumar, B . R avelo, M . Bensetti, an d P . Fernandez-Lopez, "Application of a hy brid model for the susceptibility o fa rbitrarys hape metallic wires disturbed $\mathrm{b}$ y $\mathrm{E} \mathrm{Mn}$ ear-field radiated $\mathrm{b}$ yel ectronic structures," Progress In Electromagnetics Research (PIER) B 37, pp. 143-169, 2012.

[5] E. R . R ajkumar, B . R avelo, M. B ensetti, Y . Liu, P . Fernandez-Lopez, F . D uval, a nd M. K adi, "Experimental Study o fa Computational Hybrid Method for the R adiated C oupling Modelling be tween Electronic $\mathrm{C}$ ircuits an $\mathrm{d} \mathrm{E}$ lectric $\mathrm{C}$ able," International Journal of Advanced Engineering Technology (IJAET), Vol. 3, No. 1, pp. 1-15, Mar. 2012.

[6] J. S hi, M. A . C racraft, J . Z hang a nd R . E. D uBroff, "Using Near-Field Scanning to Predict Radiated Fields," Proc. IEEE Ant. Prop. Int. Symp., S an J ose, C A, US A, Vol. 3, pp. 1477-1480, 1989.

[7] Y. Vives-Gilabert, C. Arcambal, A. Louis, F. Daran, P. Eudeline and B. Mazari, "Modeling Magnetic Radiations of E lectronic $\mathrm{C}$ ircuits us ing $\mathrm{N}$ ear-Field $\mathrm{S}$ canning Method," IEEE Tran. EMC, Vol. 49, No. 2, pp. 391-400, May 2007.

[8] Y. Vives-Gilabert, C. Arcambal, A. Louis, P. Eudeline and $\mathrm{B}$. Mazar i, “ Modeling $\mathrm{M}$ agnetic $\mathrm{E}$ missions Combining I mage $\mathrm{P}$ rocessing a nd a $\mathrm{n} \mathrm{O}$ ptimization Algorithm," IEEE Tran. EMC, Vol. 51, No. 4, pp. 909918, Nov. 2009.

[9] D. B audry, C . A rcambal, A. L ouis, B . M azari an d P. Eudeline, "Applications of the Near-Field Techniques in EMC Investigations," IEEE Trans. EMC, Vol. 49, No. 3, pp. 485-493, Aug. 2007.

[10] R. J auregui, M. P ous, M . F ernández an d F. S ilva "Transient P erturbation Analysis i n D igital R adio," Proc. IEEE Int. Symp. EMC, F ort L auderdale, F lorida, USA, pp. 263-268, Jul. 25-30 2010.

[11] T. Ordas, M. Lisart, E. S icard, P. Maurine and L. Torres, "N ear-Field Mapping S ystem to $\mathrm{S}$ can in T ime Domain the Magnetic Emissions of Integrated Circuits," Proc. PATMOS' 08: Int. Workshop on Power and Timing Modeling Optimization and Simulation, Ver. 111, 2009.

[12] C. E. Baum, "Emerging Technology for Transient and Broad-Band Analysis and Synthesis of Antennas and Scaterrers," Interaction Note 300, Proc. of IEEE, p p. 1598-1616, Nov. 1976.

[13] W. W inter a nd M . H erbrig, “Time D omain Measurement in A utomotive Applications," Proc. IEEE Int. Symp. EMC, Austin, Texas, USA, pp. 109-115, Aug. 17-21 2009.
[14] R. Cicchetti, "Transient Analysis of Radiated Field from E lectric Dipoles a nd $\mathrm{M}$ icrostrip L ines," IEEE Trans. Ant. Prop., V ol. 3 9, N o. 7, pp . 9 10-918, J ul. 1991.

[15] S. Braun, E. Gülten, A. Frech and P . Russer, "Automated Measurement of I ntermittent Signals using a Time-Domain EMI Measurement System," Proc. IEEE Int. Symp. EMC, Austin, T exas ( USA), pp. 232 -235, Aug. 17-21 2009.

[16] J. R ioult, D . S eetharamdoo an d M. H eddebaut, "Novel E lectromagnetic F ield M easuring I nstrument with R eal-Time V isualization," Proc IEEE Int. Symp. EMC, Austin, T exas ( USA), p p. 1 33-138, A ug. 17 -21 2009.

[17] R. S . Ed wards, A . C . Ma rvin a nd S . J . Porter, "Uncertainty Analyses i $\mathrm{n}$ t he $\mathrm{F}$ inite-Difference $\mathrm{T}$ imeDomain Method," IEEE Trans. EMC, Vol. 52, No. 1, pp. 155-163, Feb. 2010.

[18] L. Liu; X . C ui a nd L . Qi; “ Simulation o $\mathrm{f}$ Electromagnetic Transients of the Bus Bar in Substation by the Time-Domain Finite-Element Method," IEEE Trans. EMC, Vol. 51, No. 4, Nov. 2009, pp. 1017-1025.

[19] R. Jauregui, P. I. Riu and F. Silva "Transient FDTD Simulation V alidation," Proc IEEE Int. Symp. EMC, Fort Lauderdale, F lorida, USA, pp. 257-262, Jul. 25-30 2010 .

[20] M. A dada, “ High-Frequency S imulation Technologies-Focused on Specific H igh-Frequency Design A pplications," Microwave Engineering Europe, pp. 16-17, Jun. 2007.

[21] C. E. B aum, "Some Characteristics of Electric and Magnetic D ipole A ntennas $\mathrm{f}$ or $\mathrm{R}$ adiating $\mathrm{T}$ ransient Pulses," Sensor and Simulation Note 405, Jan. 71.

[22] B. K . S ingaraju an d C . E . B aum, "A S imple Technique $\mathrm{f}$ or $\mathrm{O}$ btaining $\mathrm{t}$ he $\mathrm{N}$ ear $\mathrm{F}$ ields of $\mathrm{E}$ lectric Dipole A ntennas f rom T heir F ar F ields," Sensor and Simulation Note 213, Mar. 76.

[23] J. Song and K.-M. Chen, "Propagation of EM Pulses Excited b y a $\mathrm{n}$ E lectric D ipole in a C onducting Medium," IEEE Tran. Ant. Prop., Vol. 41, No. 10, pp. 1414-1421, 1993.

[24] Lakhtakiaa, V . K. V aradana and V . V . V aradana, "Time-Harmonic an d T ime-Dependent $\mathrm{R}$ adiation $\mathrm{b}$ y Bifractal D ipole A rrays," Int. J. Electronics, V ol. 63 , No. 6, pp. 819-824, Dec. 1987.

[25] H. G . S chantz, “ Electromagnetic E nergy ar ound Hertzian D ipoles," IEEE Tran. Ant. Prop. Magazine, Vol. 43, No. 2, pp. 50-62, Apr. 2001.

[26] W. J un-Hong, J . L ang and J . S hui-Sheng, "Optimization of the Dipole Shapes for Maximum Peak Values of the Radiating Pulse," Proc. IEEE Tran. Ant. Prop. Society Int. Symp., Vol. 1, pp. 526-529, 1997.

[27] B. Ravelo and Y. Liu, "C omputation of Transient Near-Field $\mathrm{R}$ adiated by E lectronic Devices $\mathrm{f}$ rom Frequency D ata", Chap. 1 , F ourier T ransform Applications, Ed. by Salih Mohammed Salih, Published 
by Intech o pen science, I SBN 978-953-51-0518-3, Apr. 2012, Rijeka, Croatia, pp. 3-26.

[28] Agilent E Esof E DA, “ Overview: E lectromagnetic Design System (E MDS)," (2 008, S ep.) [O nline]. Available: http://www.agilent.com/find/eesof-emds

[29] ANSYS, "Unparalleled Advancements in S ignaland $\mathrm{P}$ ower-Integrity, E lectromagnetic Compatibility Testing," ( 2009, Jun. 1 6) [ Online]. A vailable: http://investors.ansys.com/

[30] North East Systems Associates (NESA), "RJ45 Interconnect Signal Integrity," (2010 CST Computer Simulation T echnology AG.) [Online]. A vailable: http://www.cst.com/Content/Applications/Article/Article .aspx?id=243

[31] B. Ravelo, Y. Liu, A. Louis and A. K. Jastrzebski, "Study o f hi gh-frequency e lectromagnetic tr ansients radiated by electric dipoles in near-field", IET Microw., Antennas Propag., Vol. 5, No. 6, pp. 692 - 698, A pr. 2011.

[32] B. Ravelo, Y . L iu a nd J . B . H . S lama, “ TimeDomain Planar Near-Field/Near-Field Transforms with PWS Method", Eur. Phys. J. Appl. Phys. (EPJAP), Vol. 53, No. 1, Feb. 2011, 30701-pp. 1-8.

[33] Y. Liu and B. Ravelo, "On the time-domain nearfield radiation with $\mathrm{P}$ WS method", Proceedings of the Advanced Electromagnetics Symposium (AES) 2012, Paris, France, Apr. 16-19 2012.

[34] B. Ravelo, "Electric field Extraction from H-NearField in Time-Domain by using PWS Method," Progress
In Electromagnetics Research (PIER) B, Vol. 25, 2010, pp. 171-189.

[35] Y. Liu and B. Ravelo, "Near-field map radiated by structures d isturbed b y a rbitrary tr ansient s ignals", Proceedings of the Advanced Electromagnetics Symposium (AES) 2012, Apr. 16-19 2012, Paris, France.

[36] C. A . B alanis, Antenna theory: Analysis and design, 3rd ed., Wiley, New York, USA, 2005.

[37] D. T . Paris, W . M . L each a nd E. B . J oy, "Basic theory of probe-compensated near-field measurements," IEEE Tran. Ant. Prop., Vol. 26, No. 3, pp. 373-379, May 1978.

[38] J. J. H. W ang, “An examination of the theory and practices of planar near-field measurement," IEEE Tran. Ant. Prop., 36, vol. 6, pp. 746-753, Jun. 1988.

[39] J. C. -E. S ten a nd A . H ujanen, “ Aspects o $n t$ he Phase Delay and Phase Velocity in the Electromagnetic Near-Field," Progress In Electromagnetics Research (PIER), Vol. 56, pp. 67-80, 2006.

[40] H. R . H ertz, "Untersuchungen u eber d ie Ausbreitung d er E lektrischen K raft," ( in G erman) Johann Ambrosius Barth, Leipzig, Germany, 1892.

[41] Y Liu, B. Ravelo, and P. Fernandez-Lopez, "Modeling of Magnetic Near-Field Radiated by Electronic Devices Disturbed b y Complex T ransient S ignals", Applied Physics Research (APR), Vol. 4, No. 1, Feb. 2012, pp. 3-18. 